\title{
Chapter X: Theoretical Approaches and Practical Strategies for Change Management
}

Peter McGraw and Tracy Taylor

\section{Abstract}

This chapter considers the issues surrounding the management of change within sport organisations. Specifically, the chapter will outline some of the key characteristics and types of change that may be required in sport organisations in response to different change drivers; briefly overview some of the key academic paradigms within which change can be understood; and describe some key change models that may be useful to effectively manage change. A key component of the latter approach concerns the ways in which people typically react to change and the chapter considers the way that organisations can best facilitate the introduction of changed ways of working and overcome the resistance that is typically integral to peoples' reactions. The chapter finishes with a discussion of how radical change was managed within the Australian Soccer Association.

\section{Introduction}

The ways in which people play, train, coach, manage and engage in sport are constantly changing. The changing nature of sport is driven by a complex array of social, economic, technological and political factors. Consequently, managers of sporting organisations, both professional and non professional, are confronted with the challenge of leading change initiatives whilst other members and associates of these organisations are faced with the rigours of the implementation of, and adaptation to, these change initiatives.

As in the broader business world, the pace of change for sporting organisations has increased sharply in recent times. Some of the reasons for this increasing pace can be broadly classified into the following areas: social changes which incorporate demographic and cultural aspects; economic changes linked to the globalisation of markets; the rapid 
development of new technologies (see Figure X.1); and changes in the political environments which organisations operate in. Changes in one area will more than likely stimulate changes in other areas, the interconnected nature of which is illustrated below.

Insert Figure X.1 about here

As modern society has become more commercially focused, consumer driven, and globalised, so has sport. The amateur, locally-based leisure pastime of sport and its organisation has evolved, in many instances, into a professional, highly competitive and lucrative industry with international exposure. Increasing globalisation and competitive pressures in professional sport have also led to professional sports generating substantial revenue through media rights, sponsorship and merchandising, which in turn leads to escalating salaries for players and coaches and the globalisation of the marketplace for talent.

For professional sports the ever expanding earning power of athletes, the cult of the sport super star, and the rise of the player agent, greatly facilitated by an ever expanding media and sponsorship reach, has changed the very nature of the business of sport. Professional sport has spawned a myriad of associated services and large multinational sport giants such as Octagon and IMG are no longer just sport agents but now deal in event management, hospitality, league development, licensing, media distribution and sponsorship.

At the community level local sports that do not have professional leagues or competitions have to compete with sports that have access to greater funds and sponsorship revenue. At the same time there has been increasing pressure on community sport organisations to deliver 'professional' services, from facilities to coaching, with limited resources; and to top it off there has been a worldwide decline in the numbers of citizens volunteering in sport 
organisations. Government policy, regulations and reporting requirements have led to an increased bureaucratisation of sport and escalating safety requirements have meant that even non professional sport organisations have to develop ever widening organisational capabilities to manage risk and liability.

A country's political regime and approach to sport through policy and funding can also be major change drivers. For example, after the demise of the USSR many of the newly independent states were left with a sporting system that had to be completely restructured and reorganised. In other countries a change of government or its policy platform has meant either a discontinuation of funding or the requirement to meet certain targets and management standards to attain support.

In addition to change stemming from external sources, organisations also need to manage change from internal sources. Internal change comes from the need to adapt and innovate organisational strategies, structures and processes to the changing external environment either in response to external change stimuli or in anticipation of them. For example, the introduction of web based data systems requires managers, employees and volunteers to learn new ways of responding to simple administrative matters such as membership applications, funding requests and human resource matters.

In short, there are many reasons why sport organisations have to change and equally there are many types of organisational responses to the need for change. The stimulus for change may come from broad structural changes in the macro level, external social and economic environment but the response is always initiated at the micro level of human agency (i.e. how managers of sport organisations interpret the changing external environment and their responses to it). Such responses will vary depending on the context of the organisation as defined by its external and internal environment, the content of the particular change initiative being introduced and the process adopted to introduce change (Pettigrew, 1997). 


\section{Types and characteristics of change}

The way that change is managed will relate to the nature of the change, its origins and extent to which the change impacts on the everyday activities of those involved. There are many different types of organisational change ranging from minor changes in systems or work practices that only affect a small number of people, to major shifts in the way sport organisations do business which require total organisational restructures. Figure X.2 provides a schematic overview of some of the different characteristics of change with examples from each end of a possible spectrum of alternatives.

\section{Insert Figure $x .2$ here}

As can be seen from Figure X.2 the contours of change can vary enormously first depending on the mix of characteristics and issues involved in any particular change and, secondly on the point of focus for any particular characteristic. These are discussed in the following subsections.

\section{External and Internal}

At the most fundamental level change can be regarded as inevitable and ubiquitous for all organisations, although the requirements and pace may vary depending on a range of contingencies. As discussed in the introduction to this chapter organisational change can result from changed external circumstances or internal adaptation and innovation. External factors are typically viewed to be the most powerful of the forces driving change but internal adaptation should also be acknowledged. Two academic perspectives are helpful in better understanding the relationship between external and internal change and the relationship between the two. 
First, the economic perspective outlines the core assumption that in a competitive world the survival of all organisations depends on their ability to respond to changing external competitive circumstances. The examples already given in the introduction illustrate how changing external circumstances require organisations to respond to large scale change in external environments. Second, from an organisational learning perspective organisations can be viewed as having an internal capability for adaption which will be higher in successful organisations. From this perspective change is not always directly precipitated by an external event but may occur in anticipation of the need to respond to external events. Thus, in the first instance organisational change is viewed more as a direct and largely reactive response to external stimulus whereas in the second it is viewed more as a proactive internal capability to pre-empt the need for chaotic responses.

Both perspectives are useful in theorising how change occurs and clearly point to the key role of managers and leaders in correctly interpreting the signals of the need for change and responding in an appropriate and timely manner. Managers, in their role as key players in assessing the strengths and weaknesses of organisations and the need to respond to opportunities and threats, take centre stage in the change management process.

Environmental Opportunities and Threats can come from many directions, such as:

- Increasing market competition e.g. HD sport telecasts

- Possibilities offered by new markets e.g. Soccer in Asia and Africa

- External regulatory mandate e.g. public liability insurance

- Pressure to conform to what other organisations are doing e.g. social media

- Reputational risk and credibility pressures e.g. FIFA's decision making processes in allocating host countries for football World Cups. 
In anticipating and responding to environmental change by building appropriate internal capabilities and taking appropriate actions/decisions, managers must take account of the strengths and weaknesses of the organisation in areas such as:

- Organisational learning capacity i.e. how ready is the organisation to learn new behavioural responses and techniques

- Organisational capacity for change in terms of e.g. systems flexibility

- The forces for stability and continuity and the views of key stakeholders

- Strategic clarity (or lack of) around vision, mission and values that may prevent the organisation from over-responding to short term environmental turbulence

- The balance of power between different managers and units within the organisation and whether there is a consensus on the need for and direction of change.

\section{Evolution and Revolution}

The scale and scope of change is another major variable influencing the impact on sport organisations. Evolutionary change is an incremental process whereby organisations make minor changes to their strategy, structure or practices over time in relatively stable external environments. Revolutionary change, as suggested by the name, occurs when the organisation engages in a monumental shift in its focus, structure or culture and changes the essence of the organisation. Such a dramatic change is typically driven by a need to respond to radically significant events in the sport organisation's operating environment. A well documented example of revolutionary change can be found in the work of Slack, Kikulis and colleagues (cf Kikulis, Slack \& Hinings, 1995: Amis, Slack \& Hinings, 2002) in their description and analysis of the changes in Canadian national sport organisations (NSOs) in the 1980s when federal government funding requirements necessitated the introduction of systems and structures that moved the NSOs from an amateur to professional approach to their operations. A more recent example of a revolutionary change is evidenced in the complete restructuring of the Australian Soccer Association into the Football Federation of 
Australia (FFA). This process of wide-ranging structural change was instigated following a Federal Government inquiry into the governance structure of the sport (Lock et al. 2009) and is discussed at the end of this chapter.

\section{Other Factors}

Change can also be viewed as planned or emergent. Much of the managerialist literature on change stemming back to the earliest work on the subject, presents management as concerned with planning, co-ordinating, controlling and implementing to ensure that intended changes are translated into realised changes within the organisation. From this perspective change is viewed primarily as a top down, non political and largely linear activity. Emergent change perspectives generally recognise that unforseen and unintended consequences will arise as change is implemented and that the final change outcome will be influenced by either unforseen issues or political processes driven by opponents of the planned change, particularly resistance from people within the organisation who will be most affected by it. From this perspective change can also be viewed as bottom up and political and non-linear. Related to the degree to which change is implemented as originally planned is the issue of whether the outcome of change is rational (efficiency related only) or non-rational whereby change can be driven by wider political agendas of various stakeholders which often result in compromise positions.

In this chapter the focus will be on change that is generally within the rational and contextual approaches. Rational models of organisational change suggest that change occurs through following a systematic program led by organisational strategists and leaders such as directors and managers. Contextual approaches to change differ from rational perspectives in that change is seen as the outcome of non-linear, multilevel and incremental processes that are shaped by competing group interests, organisational power and politics (Caldwell, 2005). An insightful perspective explaining non-rational, contextual and emergent organisational change can be found in the explanations contained within institutional theory. 
The underlying idea within institutional theory is that an organisation's governance structures are based on rules, norms, values, and systems of cultural meaning and that decisions are institutionally aggregated. Historical institutionalism suggests that organisations keep equilibrium through the maintenance of the status quo, while sociological institutionalism suggests that organisations seek consolidation of institutional legitimacy in a changing environment (Di Maggio \& Powell, 1983).

Change and innovations can be introduced to improve performance in one organisation which are modelled on successful techniques used in other organisations. Or changes may be introduced to 'keep up with the Jones', that is, to be seen as up to date with global trends or by switching to what is believed to be best practice. Much of the early theorising in relation to institutional theory focussed on those organisations that adopted or copied the practices of market leaders and examined the dynamics that lead to conformity among organisations. These institutional researchers found that the 'first in market' differentiation of leading edge innovating organisations shifted over time to reflect homogeneity of approaches when the organisation entered later stages of the diffusion process. McDonald's is frequently cited as a prime example of this, their business model of fast food was unique when first introduced but eventually, through franchising of the brand and with the emergence of a plethora of competitors into the marketplace, what was once a point of difference and thus an advantage, over time lost its edge and further eroded when consumers began to demand healthier, more flexible food choices. In the sport world the same points are often made about Nike, a business started by an athlete and coach who made a limited number of athlete- friendly shoes sold out of the back of co-founder Phil Knight's car. As Nike's business grew and moved beyond the track athlete to the sport shoe for everyone, so did the business model, the business outsourced production offshore which brought greater financial success and led to direct competitors and others copying this approach. 
This propensity to copy or imitate successful organisations is reflected in the premise of isomorphism (DiMaggio \& Powell, 1983, 1991), which has been explained as when 'organisations are driven to incorporate the practices and procedures defined by prevailing rationalised concepts of organisational work ... organizations that do so increase their legitimacy and their survival prospects, independent of the immediate efficacy of the acquired practices and procedures' (Meyer \& Rowan, 1977: 340). DiMaggio and Powell $(1983,1991)$ noted two types of isomorphism: competitive isomorphism that emerges from market forces, and institutional isomorphism that develops from competition for political and organisational legitimacy. The latter encompasses three elements: coercive, mimetic, and normative.

Coercive pressures are the elements that push organisational procedures and structures to conform to best practices, influenced by the factors that the organisation is dependent on for resources. A pervasive coercive isomorphic pressure for all organisations is the need to conform to changing laws. Mimetic pressures relate to the drive to reduce uncertainty whereby imitating successful peer organisations is seen as a safe strategy. The whole 'best practice' movement has this principle at its heart. Normative isomorphic pressures are a response to professionalisation, where certain types of structure and process are viewed as more legitimate than others.

In relation to normative isomorphic pressures, the emergence of managerialism in the running of sport organisations, especially in voluntary organisations has assumed dominance in the last two decades. While in professional and for profit sport organisations this focus on business acumen, target setting, performance indicators, responsibility and accountability has been underpinned by commercial viability drivers; in the non profit and community sport arena the changes have primarily been driven by government policy and funding. For example, in analysing recent UK sport policy Phillpots, Grix and Quarmby (2010) found that the imposition of County Sport Partnerships (CSPS) with highly controlled 
governance arrangements introduced another level of bureaucracy with tightly imposed targets and that 'the use of PSAs and KPIs has strengthened Sport England's control over the agencies involved in CSPs' (p.13). They concluded that 'despite notions of decentralization, new governance arrangements for CSPs appear relatively top-down and managerial' (p. 14). This finding follows on from Houlihan and Green's (2009) evaluation of the impact of New Labour's 'modernization project' on Sport England and UK Sport which they argued resulted in the objectives of both organisations being narrowed and the adoption of "business-like principles and a "command and control" regime in relationships with key frontline delivery partners' (p. 678).

\section{Models of change}

There are a number of different models that explain and explore the nature of organisational change and how best to manage it. These typically comprise five key aspects:

1. motivating for change, creating readiness to accept change and dealing with any resistance;

2. building a shared vision to which the organisation can gain commitment;

3. developing a support base that includes key stakeholders;

4. managing the transition, locking in commitment; and

5. sustaining and embedding the change through support and alignment of rewards and recognition (Waddell, Cummings \& Worley, 2000).

One of the most commonly cited change framework is Lewin's (1951) classic change model. Lewin identified three stages involved in changing organisations and people, which were:

1. establishment of the rationale and motivation to change (unfreeze);

2. empowerment of stakeholders to embrace new ways of thinking about the organisation and of working (change); and

3. finally returning the organisation to stability (refreeze). 
In the first stage of change Lewin believed that the equilibrium needs to be challenged (unfrozen) before old behaviours are left behind (unlearnt) and new behaviours are adopted. In this stage the organisation should be primed to accept that change is necessary, this means challenging the existing way of operating. One way to do this is to articulate how the change is aligned with achieving the organisation's vision and strategy. This may be prefaced by a documentation of the key issues underpinning the need for change, such as declining club membership or sport participation figures, unsatisfactory financial performance, member or customer dissatisfaction, or poor on field performance results. This first stage may also involve challenging current organisation values, attitudes, and behaviours if these are likely to block change. These stimuli then create a (planned) crisis which in turn can facilitate the buy-in and engagement context for meaningful change. Stakeholder analysis and management mapping can assist with identifying and gaining the support of key people within the organisation for the change process.

The second stage is characterised by change, as organisational staff and stakeholders start to reconsider the future and accept and support the new direction. This transitionary stage may stretch over a period of time, as those affected grapple to understand how the changes can benefit them. A good communication strategy is critical to keeping everyone informed about the changes and feeling connected to the organisation. This stage should also include the provision of opportunities for employee and key stakeholder involvement.

The organisation enters the refreeze stage when equilibrium is reached and aspects such as the organisation structure are agreed upon, new roles are filled or new ways of operating have been fully documented. To support the change it is useful to identify actions to reinforce the new elements, such as implementing reward systems aligned with the changes, and to establish explicit feedback systems to address any barriers to sustaining the change. As a component of the refreezing process it is important to commemorate the 
success of the change, reinforcing associated benefits and outcomes.

Edgar Schein (1995) extended Lewin's model by embedding a greater focus on psychology and group dynamics termed cognitive redefinition and depicted in Figure X.3 below:

\section{Insert Figure X.3 here}

In this model Stage 1 suggests that the motivation to change (unfreezing) is linked to the premise that past observational learning and cultural influences drive behaviour. Schein (1996: 27) felt that change was 'a profound psychological dynamic process.' Therefore, he suggested that new forces for change need to be introduced or some of the existing aspects that are perpetuating the behaviour need to be removed. Three sub-processes underpin readiness and motivation to change.

1. Disconfirmation: where present conditions lead to dissatisfaction.

2. The pressure to change creates survival anxiety- which may take several forms from fear of incompetence to fear of loss of personal identity or group membership.

3. Learning anxiety associated with learning something new can trigger defensiveness and/or denial, scapegoating, and manoeuvring.

Those involved in the change need to feel safe before they engage with the process and move to accept new ways of thinking and/or doing things. If the survival anxiety is greater than the learning anxiety or, preferably, the learning anxiety is reduced, then the unfreezing proceeds. The learning anxiety can be reduced by increasing psychological safety through training, performance coaching, support groups and other such mechanisms.

In Stage 2 change is facilitated when there is adequate dissatisfaction with the current conditions and there is acceptance to change. The disparity between the present state and 
that being proposed should be clear. Activities that assist in making the change include replication of role models and using trial-and-error learning to devise individualised solutions.

To lock in the change as permanent (refreezing Stage 3) new behaviour should become habitual, and include developing a new self-concept and identity and instituting new interpersonal relationships. Refreezing seeks to provide an environment where the change is aligned with the changed organisational culture, policies and practices.

Another way of looking at change is embodied in contextual or processual change theory which emerged in the 1980 s as a rejection of rational, planned change. It was argued that the latter was too prescriptive and failed to recognise the inherent complexity of change. According to this perspective Pettigrew (1987) and his colleagues saw change as involving complex, dynamic and non-linear politically and culturally influenced processes. This approach also notes the importance of understanding the sequencing and pacing of different types of changes. The reality of change in sport organisations being complex and non-linear is evident in the 12 year study of change in 36 Canadian sport organisations by Amis, Slack and Hinings (2004). These researchers found that revolutionary change was accomplished by pacing the changes so that after each change the organisation had time to settle into the new way of doing things, establish trust and relationships and then engage in the next change.

Another change approach is seen in the in the work of Dunphy and Stace (1990) and Stace and Dunphy (2001). This influential model combined internal and external factors into a contingency theory matrix. This model seeks to explain how organisations adjust to their external environments and the scale and scope of change required (from fine tuning to corporate transformation) via a standardised, but comprehensive, list of managerial styles ranging from collaborative to coercive. In total the model canvasses 16 possible styles of change but five main approaches are noted (see Figure X.4): 
1. In developmental transitions there is regular change as organisations adapt to their external environments. Here the leadership style is most appropriately consultative where the leader acts to gain shared commitment from organisational stakeholders on the need for continual improvement.

2. In task-focused transitions the management style is most appropriately directive with managers seeking compliance from organisational stakeholders about changes to operational requirements in certain areas. Although strongly directed from the top there is scope in this type of change for a more consultative approach as change is implemented lower down the organisation.

3. In contrast, in charismatic transformations the need for radical transformation is led by an inspiring leader who can symbolically mobilise the emotional commitment of staff and in so doing lead the organisation in a new direction.

4. Turnarounds are situations where organisational survival is perceived to be at stake and radical transformations are led by command and control oriented leaders who force change via coercive and directive commands with limited emphasis on employee engagement or commitment.

5. The fifth category of Taylorism is associated with fine-tuning and paternalistic approaches to change.

Each of the approaches noted above is associated with a consequent 'path of change' (Stace \& Dunphy, 2001; 108-93) that takes account of the long term consequences of different approaches. For example, organisations that rely a lot on fine-tuning may also have to contemplate turnarounds or charismatic transformations at times to reinvigorate themselves and where charismatic transformations occur they may need to be supported over time by developmental or task-focused transitions to maintain momentum. In related empirical work Stace and Dunphy (2001) found that the most commonly used change processes were hybrid forms that combined directive and consultative styles although the exception to this was turnarounds which were more likely to be directive and/or coercive in 
style. In addition, the empirical research suggested that the most successful organisations used consultative and directive change management styles and the least successful were more likely to use Tayloristic fine tuning. Overall, the main conclusions were that more effective managers and organisations tended to be comfortable using different approaches depending upon the prevailing circumstances. 


\section{Insert Figure X.4 here}

\section{Resistance to change}

Whilst it would be an overstatement to say that people always resist change, it is certainly a commonly reported response from people who are presented with the need to change without being involved in the initial decision. People tend to be resistant to change because they have an investment in the status quo (position, prestige, rewards, comfort level, status) but change, especially when imposed by others, also offers an unbalanced 'psychological bargain'. In effect the change leaders are asking organisational members to trust them in relation to an uncertain future where many known and hard won things may be jeopardised. Resistance can come from a number of sources, from the requirement for new skills, changed norms or perceived loss of status, power or conditions. This can lead to individual or group feelings of frustration, insecurity or anger, and result in employee or volunteer turnover or regressive or aggressive behaviours. Stages in the response to change process have been suggested to encompass psychological reactions such as denial; resistance; exploration; and commitment. Also, uncertainty about the future can create fear and a perception of threat associated with lack of control. The most commonly asked question in relation to change processes is 'what does this mean for me?' Therefore anticipating and dealing with resistance is paramount and the organisation should have a communications plan for keeping people informed as a key part of managing change processes.

Planning for change and thus minimising resistance can be tackled in a number of ways. A change plan should clearly state why change is needed and how it will impact groups of people and, at some stage, each individual. Also, change responsiveness can be facilitated by creating a climate of trust through supporting and involving affected staff and volunteers 
in the change process and allowing them to have some input in the either the direction or implementation of change.

One of the best known and influential prescriptive models of managing change to overcome resistance can be found in the Kotter's Eight Step Model (See Figure X.5). This model emerged from Kotter's (1995) research based observations of why change programs fail, which was further developed in by Kotter (1996) and Kotter and Cohen (2002).

\section{Insert figure X.5 here}

The Kotter model is a classic example of a top-down change management process and is likely to work best for change projects that are driven by the top leadership of an organisation. Kotter acknowledges that his somewhat linear model tends to over simplify what is often a more complex reality and that even successful change processes are subject to surprising and unforeseeable developments that can make them messy. However, Kotter maintains that all elements of the eight steps must be addressed and that skipping steps will only create the illusion of speed and progress and lead eventually to poorer results.

In terms of management style Kotter suggests that managers follow a 'see-feel-change' pattern in which problems are presented in a way which captures the attention of stakeholders and taps into their feelings about the need for change at a profound level. An example of this is given in relation to step 1 (creating a sense of urgency) where Kotter recommends 'bringing the outside in' so that stakeholders such as employees come face to face directly with the nature of the external issue driving change.

The major strengths of the Kotter model is that it outlines clear and well researched steps 
which provide guidance on how to manage change, focuses on the importance of getting buy-in from employees, acknowledges the need to build a political consensus with key stakeholders and combines the need to change systems with the need to manage the reactions of groups and individuals impacted by change. The limitations of the model are that it is best suited to top-down change processes and that it does not provide room for participation inputs which fundamentally challenge the initial strategy. In this sense the genuineness of the participation mechanisms can be questioned.

\section{Summary and conclusion}

This chapter has provided an overview of some of the key issues driving change in sport organisations incorporating economic, demographic, technical, social and political sources. The chapter has outlined key characteristics and types of change that may be required in sport organisations in response to different change drivers and suggested that change management competence is a key competence for organisations adapting to rapidly changing environments.

Key change models that are widely regarded in the academic and practitioner literature have been discussed and reviewed. These models provide a useful template for managers confronted with the need to effectively manage change, as well as recommendations to evaluate context related strategy choices. Some of the key components of the approaches discussed have concerned the ways in which people typically react to change and the way that sport organisations and their managers can best facilitate the introduction of changed ways of working to maximise benefit and to overcome the likely resistance that is often central to the reactions of other organisational members. In conclusion, we suggest that an understanding of the forces driving change and a sensitivity to the alternative approaches outlined in this chapter are critical for managers of modern sport organisations. Equally, well developed change management skills, especially those related to overcoming resistance are 
also vital. We noted at the start of this chapter that the pace of change has increased dramatically in sport organisations during the last two decades. In closing we note no sign of a reduction in either the scale or scope of change or the need for managers to be skilled in handling it. 


\section{A CASE OF CHANGE}

\section{Change or die: Reforming football governance practice in Australia}

(Daniel Lock)

\section{Introduction}

In Australia, Association football (previously known as soccer and now simply football) has endured a turbulent history, marred by corruption, hooliganism, nationalistic rivalry and mismanagement (Crawford, 2003). Despite boasting the highest participation figures of any team sport in Australia (Australian Sports Commission, 2002, 2003, 2004, 2005, 2006), football has consistently failed to attract a sufficient supporter base to lure the sponsors and media coverage required for a solvent and competitive professional sporting code and national competition (Lock, 2009). To compound the issues with national level governance, Australia's national team - The Socceroos failed to qualify for the FIFA World Cup finals between 1975 and 2005 and the National Soccer League (NSL) floundered, which served to further marginalise football from mainstream Australian sporting culture.

In 2003, following increasing public pressure for change the Australian Federal Government intervened, commissioning a report into 'The Structure, Governance and Management of Soccer in Australia' (Crawford, 2003). This report sought to address the issue of providing a suitable figurehead to oversee a revolutionary change process to improve existing management practices of football governance in Australia. The Crawford Report instigated a pronounced process of change to Australian football governance. It was, as Lynch (2003: 19) asserted, time for change 'the game can no longer be held back by a management and organisational culture historically characterised by deal making, factionalism and politics.' The chosen figurehead, Frank Lowy and his newly constituted board headed quickly into a process of organisational change, founded specifically around enacting a new and 
meticulously prepared strategic plan. In the strategic business plan unveiled by the Australian Soccer Association (ASA) (2004: 2-3) (ASA) four areas of change were identified. These were:

1. People and organisational culture

2. Stakeholder management

3. Game and core product

4. Commercial and marketing

These areas of change sought to act on clearly identified and widely agreed problems within football in Australia. As incoming CEO John O'Neill (2006) surmised (in his address to the Australian Press Club) the situation when he became incumbent:

'Relations with players were strained and unworkable, sponsorship and media deals flawed and untenable, relations between the various stakeholders were dysfunctional, and Australian Soccer had a somewhat justified reputation for nepotism parochialism, jingoism and shoddy practices, and was constantly under attack in the media.'

\section{Change agenda}

To address the recommendations of The Crawford Report, the ASA developed a plan which outlined a strategy to: create a new league; improve international performances; attract credible corporate partners; and to reform the factionalised organisational structure of the ASA to better serve its stakeholders (Australian Soccer Association, 2004). For the purposes of this case study, the reformation of stakeholder management processes and creating a positive new organisational culture are the focus. The reformation of game and core product and development of commercial and marketing relationships are briefly covered after as they 
were key to improving perceptions of the ASA in Australia following the changes to organisation structure and culture.

Calls for radical changes to football in Australia were not a novelty. The Bradley Report outlined a blueprint for changes to football's administrative structure in 1990. However, the decision making process associated with previous incarnations of football governance in Australia allowed individuals and clubs with vested interests to block reform (Solly, 2004). When the Australian Federal Government intervened in 2003 to reform football in Australia, they offered AU\$15 million in grant and loan funding to administer the first steps of change. To secure this money, the recommendations of the Crawford Report were to be adopted in full, which circumnavigated the previous issues associated with change processes being blocked by bureaucracy (Solly, 2004). To initiate the process of radical changes, the ASA itself was required to change fundamentally. These changes are defined below.

\section{People and organisational culture}

To reform the governance structure at the ASA, it was evident that a shift in personnel was required. The existing board of the ASA, despite attempts to resist were removed soon after the Crawford Report was published (Solly, 2004). The Crawford Report identified that ‘appropriately skilled' individuals were required as change agents and that the current administration was not fit to implement the changes delegated (Crawford, $2003: 4$ ). Initially a suitable figurehead was sought to oversee the changes and remove the existing board. The review committee recommended Australian business tycoon and property magnate, Frank Lowy as a suitable figurehead to supervise the change process at the ASA. His recruitment was based on three factors. First, Lowy had the backing of the Federal Government to initiate the changes and override attempts to block the process as had been encountered during previous attempts for reform (Solly, 2004). Second, Lowy had global networks and 
respect that would be vital in improving Australia's standing within Oceania, Asia and FIFA. Third, Lowy was an extremely well respected businessman and capable of recruiting high profile administrators as appropriately skilled change agents to transform football in Australia (Solly, 2004).

On assuming the role of Chairman, Lowy began an extensive search for a skilled administrative team to develop and carry through the strategic objectives outlined in the Crawford Report (Australian Soccer Association, 2004; Crawford, 2003). Extensive research was undertaken before recruiting ex-Australian Rugby Union (ARU) aficionado John O'Neill as CEO (Cockerill, 2004). O'Neill had a formidable record in the administration of the ARU having been involved in the bid for the 2003 Rugby World Cup and the day-to-day running of a top-level Australian sport. In addition, the ASA's Strategic Plan also sought to establish an outstanding commercial team (Australian Soccer Association, 2004). This was formed to introduce best practice into the ASA and to shift the organisational culture away from the nepotism and other dubious practices of the past (O'Neill, 2006).

Moving beyond the poor practices of previous governances required considerable strategic planning and a thorough adherence to the recommendations of the Crawford Report. To introduce best governance practice at a national governance level, The Crawford Report required that the ASA clearly define, differentiate and separate duties of board members and employees (Crawford, 2003). This involved articulating a clear organisational plan to improve the efficiency and effectiveness of the ASA. In addition to the recommendations of the Crawford Report, the ASA's Strategic Plan sought to develop a clear succession management process so the new organisational structure and culture was not reliant wholly on people, but sound practice, instead (Australian Soccer Association, 2004). Beyond the scope of the internal function of the ASA, The Crawford Report was specific that 
relationships with stakeholders in Australia and internationally should be improved. This facet of change is discussed here.

\section{Stakeholder management}

Two key weaknesses in current stakeholder management practices were identified in the Crawford Report and targeted in the ASA's strategic plan (Australian Soccer Association, 2004). These were the need to improve relationships and management of state based organisations and to develop relationships with international stakeholders at continental and global levels (Australian Soccer Association, 2004).

Firstly, the Crawford review committee presented findings showing that the ASA did not have the support of the majority of its domestic stakeholders, including state and local football associations (Crawford, 2003; Solly, 2004). John O'Neill (2006) articulated the problems this caused: 'for too long, this sport [football] has been fractured with local committees, mostly with the best of intentions, developing their own regulations.' Therefore, there was no consistency of delivery from the national governing body through to the state and local football associations (Crawford, 2003). Delivery was determined at state and local levels, which was ad-hoc and reliant on the expertise of individuals present in localities, which is not a sound management framework.

The Crawford Report recommended that the ASA develop a coherent strategy for national, state and local delivery and management of football and that all state and local associations should be members of the national governing body (Crawford, 2003). The ASA Strategic Plan acted on this recommendation by introducing service contracts between the ASA and each state and territory of Australia (Australian Soccer Association, 2004). A specific point of 
strategic change was to 'ensure that state members' administration and football structures mirror those of the ASA' (Australian Soccer Association 2004: 25). By ensuring that each state and local association shared a common purpose with the ASA and had a similar organisational structure, O'Neill (2006) hoped that 'new national regulations would provide the framework for all clubs and districts to administer the game correctly.' By correctly, O'Neill was referring to states and localities delivering football based on best practice observed from around the globe and disseminated by the ASA.

Secondly, the ASA set out to develop a more prominent relationship with international football stakeholders: namely FIFA and the Asian Football Confederation (AFC) (Australian Soccer Association, 2004). Both attempts to develop international stakeholder relationships were conceived to promote Australia's marginalised position in the administration of football globally (Australian Soccer Association, 2004). Strategic conversations with the AFC were used to generate a potential shift into the AFC from the Oceanic Football Confederation (OFC). Shifting to the AFC was preferential for two reasons: One, the AFC provided a far more powerful, influential and organised confederation within FIFA's structure. Two, the OFC included minimal competitive fixtures, which were played against weak opposition, which failed to garner public attention. The AFC offered four or five places (dependent on the host) to the OFC's one in the FIFA World Cup qualifying procedure and the potential for participation in the Asian Cup (International) and the Asian Champions League (Club), which offered a renewed international appeal for the ASA and an increase in the number of high profile competitive fixtures hosted in Australia (Australian Soccer Association, 2004). The broader impact of the changes to governance structure and stakeholder management practices is discussed here. 
The change processes described during this case study created a period of considerable success for football in Australia between 2005-2006. The ASA was renamed the Football Federation Australia in 2004 (FFA), to create a clean break from "old soccer", thus launching "new football" to tap into the global nature of the sport (Cockerill, 2005). In 2005, the ALeague was launched and the Socceroos qualified for the FIFA World Cup. 2006 saw Australia join the AFC, which gave the Socceroos access to an improved pathway to FIFA World Cup qualification and the Asian Cup and all A-League teams the opportunity to qualify for the Asian Champions League (Football Federation Australia, 2010a). Additionally, it provided Australia with a far stronger standing within the FIFA structure and an opportunity to develop better networks with international stakeholders. In 2010 the Socceroos again participated in the FIFA World Cup.

Off the field, the FFA secured a media-rights deal with FOX Sports Television to broadcast A-League and international matches exclusively on Pay-Television (which was renegotiated shortly before the FIFA World Cup in 2006 for a significant increase in value). Additionally the FFA attracted the support of high-profile corporate sponsors including Hyundai, Qantas, Optus, Nike, Solo, Westfield and NAB (Football Federation Australia, 2010b). The accrual of a significant group of corporate sponsors was aided by the FFA's decision to join the AFC as it provided corporate partners with access to the lucrative Asian business market through support of an Australian sport.

Notwithstanding the on and off field success the management of stakeholders at a State and local level has continued to trouble the FFA. The culture of mismanagement that preceded 2004 led to State organisations holding considerable autonomy, which they have fought hard to maintain. Slowly the FFA has been able to pull the organisations into their structure: First through the changing of their titles to reflect "football" not "soccer"; Second through each 
State and territory becoming a member of the FFA, as stipulated in the Crawford Report (2003) and ASA Strategic Plan (Australian Soccer Association, 2004). This process has been arduous, with some State associations resisting membership until as recently as 2010 .

Despite the radical changes that were implemented from 2004-2006, the process of change has not been straightforward since. The FFA has endured a revolving door of staff maintenance, with John O'Neill and the majority of the commercial team departing soon after the FIFA 2006 World Cup in Germany. Although Frank Lowy remains as Chairman of the FFA, the turnover of staff has tested the succession planning processes (Australian Soccer Association, 2004). Lowy has continued to oversee the recruitment of a high profile commercial team and CEO, but football has undoubtedly entered a period of consolidation since 2006.

\section{Linking the case to Key Chapter Concepts.}

The FFA case illustrates many of the concepts discussed in the body of the chapter and provides a vivid illustration of large scale, managerially led change in an important sporting organisation.

In relation to the types of change discussed in Figure X.2 and the associated commentary, the FFA case is a clear example of organisational change that is 'root and branch' in scale and scope. The drivers for change in the FFA case were a widespread recognition that the pre change administrative structures and processes were flawed beyond redemption and required a transformational turnaround led by a new and powerful management team with a clear mandate. Clearly, the key engine of the reform was economic with government funding being conditional on the implementation of new structures and new TV and commercial contracts supporting the rationale for the revised operations once established. Although the 
change had an overt and highly public political agenda to improve Australian football and rid it of "shoddy practices", once under way the language of change was primarily concerned with professionalism, administrative efficiency, implementing globally accepted managerial systems and becoming economically self sustaining by providing a high quality and attractive product. Additionally the change process in the FFA case was linear in that it was managed over time in accordance with a clearly envisioned set of goals and outcomes and not allowed to deviate from these, it was long run (and continues at the time of writing), and involved many factors traversing the spectrum of macro related systems and structures and micro aspects relating to the way individuals were expected to behave.

The management approach in the FFA case is an interesting illustration of the managerial actions required to overcome resistance as espoused by Kotter (1995). A sense of urgency was created by the economic incentives on for successful change and a clear articulation of the opportunity cost of continuing without reform. A powerful guiding coalition was established to oversee the change starting at the board level and continuing with the appointment of a new CEO and new managerial team. The vision for the new organisation was articulated very strongly and communicated consistently as a reference point during the long-term change implementation process as a way of overcoming resistance along the way. Short-term wins to show that change was working were delivered through the success of the A League and the national team in qualifying twice for the FIFA World Cups of 2006 and 2010. Lastly momentum was maintained through the introduction of new managerial systems and the longer-term establishment of a different culture for FFA.

\section{Summary}

This case has outlined both the necessity for change and the strategic planning processes that underpinned the reformation of football in Australia. Although the governance of football has developed markedly since 2003 , the sport still faces significant challenges as it 
continues to overcome the mismanagement of previous governance. The future of football in Australia has been given a lifeline by the Australian Federal Government's intervention; however, the process of change is incomplete and will provide an ongoing challenge to the management team at the FFA to satisfy the needs of those domestic stakeholders that are responsible for ensuring the coherent and best practice delivery and management that is fundamental to the ongoing management of football in Australia. 


\section{References}

Amis, J., Slack. T. and Hinings, C.R. (2004) 'The pace, sequence, and linearity of radical change', The Academy of Management Journal 47: 15-39.

Amis, J., Slack. T. and Hinings, C.R. (2002) 'Values and organizational change', The Journal of Applied Behavioural Science 38: 436-465.

Australian Soccer Association, Sydney, (2004) 'Strategic Business Plan: Creating a sustainable, flourishing game'.

Australian Sports Commission (2002) 'Exercise, Recreation and Sport Survey (ERASS)', Canberra: Australian Sports Commission.

Australian Sports Commission (2003) 'Exercise, Recreation and Sport Survey (ERASS)', Canberra: Australian Sports Commission.

Australian Sports Commission (2004) 'Exercise, Recreation and Sport Survey (ERASS)', Canberra: Australian Sports Commission.

Australian Sports Commission (2006) 'Exercise, Recreation and Sport Survey (ERASS)', Canberra: Australian Sports Commission.

Boyle, R. and Haynes, R. (2009) Power play: Sport, the media and popular culture, Edinburgh: Edinburgh University Press.

Caldwell. R. (2005) Agency and change: Rethinking change agency in organizations, New York: Routledge.

Chadwick, S. (2009) 'From outside lane to inside track: sport management research in the twenty-first century', Management decision 47: 191-203. 
Cockerill, M. (2005) 'Lowy targets young, welcomes old', Sydney Morning Herald, p. 35, August $9^{\text {th }}$.

Cockerill, M. (2004) 'O'Neill taking off without enough baggage', Sydney Morning Herald, p. 74 , March $13^{\text {th }}$.

Collins, D. (1998) Organizational change: Sociological perspectives, London: Routledge.

Collis, J. and Hussey, R. (2009) Business research: A practical guide for undergraduate and postgraduate studies, 3rd Ed., Basingstoke: Palgrave-McMillan,.

Crawford, D. (2003) 'Into the structure, governance and management of soccer in Australia', Report of the Independent Soccer Review Committee, Canberra: Australian Sports Commission.

DiMaggio, P.J. and Powell, W.W. (1983) 'The iron cage revisited: Institutional isomorphism and collective rationality in organizational fields', American Sociological Review, 48: 147160.

DiMaggio, P.J. and Powell, W.W. (1991) The new institutionalism in organizational analysis, Chicago: University of Chicago.

Dunphy, D. and Stace, D. (1990) Under new management: Australian organizations in transition, Sydney: McGraw-Hill.

Football Federation Australia Limited, 2010a, 'About the FFA', from: http://www.footballaustralia.com.au/2009InsideFFA/default.aspx?s=insideffa2009 abo ut new (accessed on 10.11.2010).

Football Federation Australia Limited, 2010b, 'Partners', http://www.footballaustralia.com.au/2009InsideFFA/default.aspx?s=insideffa ffa partners new (accessed on 10.11.2010). 
Hutchins, B. (2008) 'Signs of meta-change in second modernity: the growth of e-sport and the World Cyber Games', New Media and Society 10: 851.

Karaiskos, D., Kourouthanassis P. and Giaglis, G. (2010) User acceptance of pervasive information systems: evaluating an RFID ticketing system, Conference paper. Retrieved from: Google Scholar, T. Kriemadis, C. Terzoudis, and N. Kartakoullis, 'Internet marketing in football clubs: a comparison between English and Greek websites' Soccer \& Society 11: 291-307.

Kikulis, L.M., Slack, T. and Hinings, C.R. (1995) 'Toward an understanding of the role of agency and choice in the changing structure of Canada's national sport organizations', Journal of Sport Management 9: 135-152.

Kotter, J.P. and Cohen, D.S. (2002) The Heart of change: Real life stories of how people change their organisations. Boston, MA: Harvard Business School Press.

Kotter, J.P. (1995) 'Leading change: Why transformational efforts fail', Harvard Business Review, 59-67.

Kotter, J.P. (1996) Leading Change, Boston, MA: Harvard Business School Press.

Lange, K., Nicholson, M., and Hess, R. (2007) 'A new breed apart? Work practices of Australian internet sport journalists', Sport in Society 10: 662-679.

Lewin, K. (1951) Field theory in social science: Selected theoretical papers. In D. Cartwright (Ed.), New York: Harper and Row.

Lock, D. (2006) 'Fan perspectives of change in Australia's A-League', Soccer \& Society, 10: 109-123. 
Lock, D., Darcy, S. and Taylor, T. (2009) 'Starting with a clean state: Analysis of member identification with a new sports team', Sports Management Review 12: 15-25.

Lynch, M. (2003) 'There's only one way forward', The Age, p. 19, April $9^{\text {th }}$.

Meyer, J. and Rowan, B. (1977) 'Institutionalized organizations: Formal structures as myth and ceremony', American Journal of Sociology 83: 340-363.

O’Neill, J. (2006). National Press Club

Address, http://www.footballaustralia.com.au/default.aspx?s=insideffa newsfeature features item\&id=10252 (accessed 30.10.2007).

Pettigrew, A. (1997) 'What is processual analysis?' Scandinavian Journal of Management 13: $337-48$

Ross, S. (2010) Sport Technology, London: Evan Brothers Limited.

Santomier, J. and Shuart, J. (2008) 'Sport new media', International Journal of Sport Management and Marketing 4: 85-101.

Schein, E.H. (1996) 'Kurt Lewin's change theory in the field and in the classroom: notes towards a model of management learning', Systems practice 9: 27-47.

Slack, T. and Parent, M. (2006) Understanding sport organizations: The application of organization theory, Champaign, III.: Human Kinetics.

Solly, R. (2004) Shoot Out: The passion and the politics of soccer's fight for survival in Australia, Milton: John Wiley \& Sons.

Stace, D. and Dunphy, D. (2001) Beyond the boundaries: Leading and recreating the successful enterprise, $2^{\text {nd }}$ Ed., Sydney: McGraw-Hill. 
Turner, P. and Shilbury, D. (2010) 'The impact of emerging technology in sport broadcasting on the predictions for interorganizational relationship (IOR) formation in professional football', Journal of Sport Management 24: 10-44.

Waddell, D., Cummings T., and Worley, C., (2000) Organisation development and change, Melbourne: Nelson Thompson Learning.

Webb, T. (2007) 'How European sport has changed the way it sells its sponsorship packages', Journal of Sponsorship 1: 20-27. 


\section{Figure X.1: New technologies - a changing sport landscape}

Sport organisations worldwide continually grapple with a myriad of new technologies that seem to emerge on a daily basis. One technology that has been embraced almost universally is what is generically termed 'new media', that is the development of interactive websites, streaming audio and video, chat rooms, online communities, web advertising, and virtual reality environments among others (Santomier \& Shuart, 2008).

YouTube is increasingly used by sports governing bodies, clubs and fans to distribute audiovisual coverage of sporting events. The National Hockey League (NHL) in the North America was one of the first governing bodies of sport to launch its own YouTube channel in 2006. This enabled the NHL to bypass traditional television outlets, open up other revenue streams through advertising and subscription and get direct editorial control how the sport is produced (Boyle \& Haynes, 2009). In 2007, this model was followed by Chelsea Football Club, which launched their own YouTube channel to showcase news and interviews with players and the manager.

Another example is technology-based ticketing systems that have been introduced by all major sport stadia around the globe. The technologies most commonly used are magnetic stripes tickets/cards, electronic tickets via Internet, smart cards and mobile ticketing systems. Most systems are a cheaper and more effective way to handle ticket sales for organisations and allow 24/7 purchasing, last minute discounts and other benefits. These systems have radically changed the way stadia and sport organisations operate. Currently ticketing is often outsourced to ticket seller and distributer companies, such as Ticketed and Ticketmaster, which reduces operational issues and costs (Karaiskos, Kourouthanassis \& Giaglis, 2007). 
New technologies are now prominent in the development of sports equipment and clothing.

This is a challenge for many sport organisations that must continuously adapt competition rules and policies. A recent example that caused much public attention and challenged all parties involved was the revolutionary Arena swimsuits used at the 2009 World Swimming Championships in Rome, where dozens of records were broken due to the use of the new material polyurethane (a form of plastic). The suits were consequentially banned on the grounds that they artificially enhanced performance (Ross, 2010). As this example illustrates, the introduction of new technology forces sport organisations to constantly adapt to technological developments.

Modern technologies have changed the world of sport. Technological developments and innovations not only create opportunities for new organisations to enter the market place but create whole new markets - such as new sports (Boyle \& Haynes, 2009). Also, modern technologies have changed the structure of organisations (Slack \& Parent, 2006), the way they operate and their inter-organisational relationship (for example in between sport producer and sport broadcaster). On the one hand, sports organisations have become more regulated and interdependent as is shown by the symbiotic relationship between sport and the media (Lange, Nicholson \& Hess, 2007; Turner \& Shilbury, 2010). On the other hand, modern technologies make organisations more independent and self-regulated as new communication channels such as the Internet enable them to communicate directly with fans, participants and others (Hutchins, 2008; Webb, 2007).

Many sports organisations have become highly professional as they embrace new technologies (Webb, 2007). Whether these imply more benefits than costs for an organisation depends on many factors. With the right skills and knowledge, sport organisations can definitely benefit from modern technologies in many ways such as through a more efficient operation or more communication channels that reach out internationally (Slack \& Parent, 2006; Santomier \& Shuart, 2008; Kriemadis, Terzoudis \& Kartakoullis, 
2010) or other business-generating opportunities (Webb, 2007). However, modern technologies often imply additional costs as they can be very expensive and qualified staff are needed (Santomier \& Shuart, 2008; Slack \& Parent, 2006). Therefore, it is often a challenge for sports organisations to embrace modern technologies, especially when resources are scarce (Santomier \& Shuart, 2008).

The rapid development of technologies in sport also forces sport organisations and clubs to acquire more high-tech and sophisticated training and athlete development methods in order to stay competitive. This often implies high costs but opens up new avenues of revenue as athletes can be better developed and assessed (Chadwick, 2009). Regardless of the nature of innovations, sports organisations must seek to quickly adapt to modern technologies to manage their ongoing activities and operations (Turner \& Shilbury, 2010). 
Figure 2. A schematic overview of different change issues

\begin{tabular}{|c|c|c|}
\hline Characteristic/lssue & \multicolumn{2}{|c|}{ Alternatives from each end of spectrum } \\
\hline Stimulus & External & Internal \\
\hline Scale and Scope & Revolutionary & Evolutionary \\
\hline Strategy and Timing & Planned & Emergent \\
\hline Language & Rational & Non - rational \\
\hline Drivers/Leaders & Top Down & Bottom Up \\
\hline $\begin{array}{l}\text { Environmental Determinants } \\
\text { and Duration }\end{array}$ & $\begin{array}{l}\text { Equilibrium (Single issue and } \\
\text { non continuous) }\end{array}$ & $\begin{array}{l}\text { Non Equilibrium (Continuous } \\
\text { change and multiple issues) }\end{array}$ \\
\hline Power and resources & $\begin{array}{l}\text { Non political e.g. improving } \\
\text { internal efficiency }\end{array}$ & $\begin{array}{l}\text { Political e.g. power struggle } \\
\text { between different } \\
\text { stakeholders over } \\
\text { organizational mission, } \\
\text { resource allocations etc. }\end{array}$ \\
\hline Direction & Linear & Non Linear \\
\hline Emphasis & $\begin{array}{l}\text { Macro - organisational } \\
\text { strategy/structure/systems } \\
\text { and processes }\end{array}$ & $\begin{array}{l}\text { Micro - behavioural change } \\
\text { at the level of individuals }\end{array}$ \\
\hline
\end{tabular}


Figure 3: Schein/Lewin Model

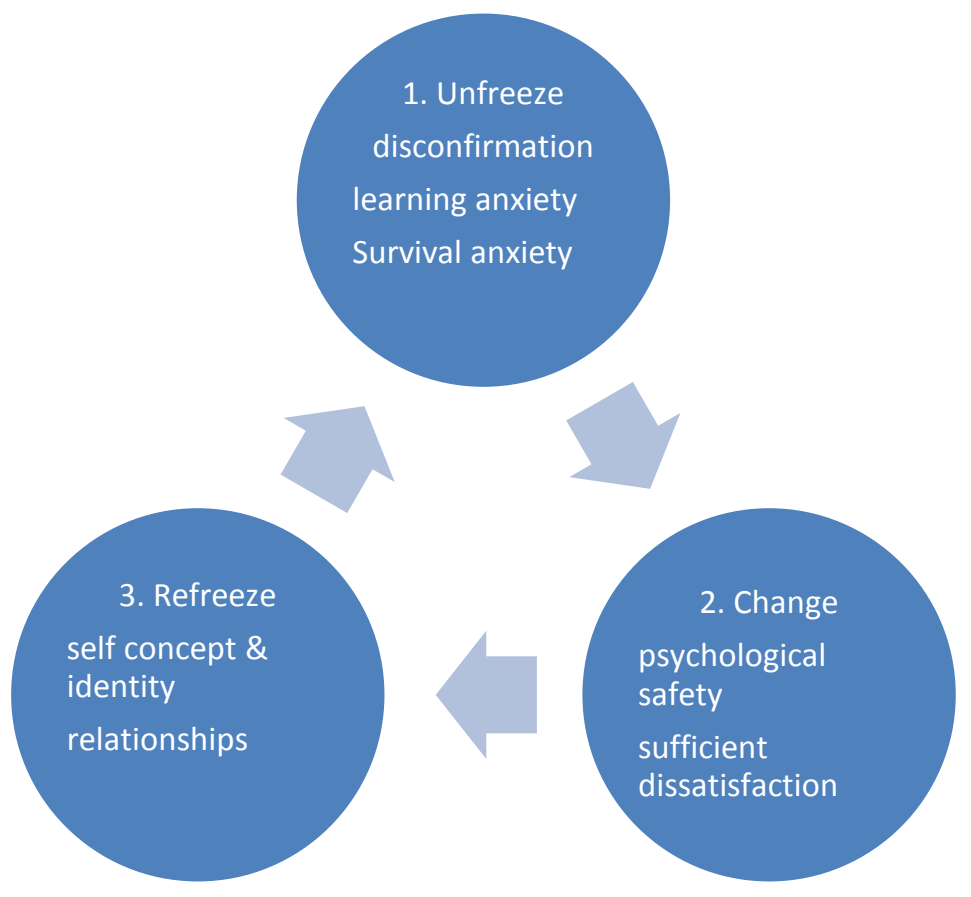


Figure 4: The Dunphy and Stace Change matrix

\section{Style of change}

Management

$\begin{array}{llll}\text { Fine tuning } & \text { Incremental } & \text { Modular } & \text { Corporate } \\ & \text { adjustment } & \text { Transformation } & \end{array}$

Transformation

\begin{tabular}{l|c|c|}
\cline { 2 - 3 } Collaborative & Type 1 & Type 2 \\
Participative evolution & Charismatic transformation \\
\cline { 2 - 3 } Consultative & Type 3 & Type 4 \\
\cline { 2 - 3 } Directive & Forced evolution & Dictational transformation \\
\cline { 2 - 2 } & & \\
\hline
\end{tabular}

Coercive

Source: Stace \& Dunphy, 2001: 109

Figure X 5:Kotter's 8 Step Model

1. Establishing a Sense of Urgency: Examining market and competitive realities, identifying and discussing crises, potential crises, or major opportunities. 
2. Forming a Powerful Guiding Coalition: Assembling a group with enough power to lead the change effort. Encouraging the group to work together as a team.

3. Creating a Vision: Developing strategies for achieving that vision. Creating a vision to help direct the change effort.

4. Communicating the Vision: Using every vehicle possible to communicate the new vision and strategies. Teaching new behaviours by the example of the guiding coalition.

5. Empowering Others to Act on the Vision: Getting rid of obstacles to change Changing systems or structures that seriously undermine the vision. Encouraging risk taking and non-traditional ideas, activities and actions.

6. Planning for and Creating Short-Term Wins: Planning for visible performance improvements. Creating those improvements. Recognising and rewarding employees involved in the improvement

7. Maintain focus and momentum. Beware of declaring victory too early and recognise that fundamental change requires a long time before new behaviours become embedded.

8. Institutionalising New Approaches: Articulating the connections between the new behaviours and corporate success. Developing the means to ensure leadership development and succession. 